\title{
10. Modification of Sodium and Potassium Channel Activities of Squid Giant Axon by Non-Electrolytes
}

\author{
By Fumio Kukita and Shunichi Yamagishi \\ Laboratory of Membrane Biology, Department of Cell Physiology, \\ National Institute for Physiological Sciences, \\ Myodaiji, Okazaki 444 \\ (Communicated by Yasuji KATsukI, M. J. A., Jan. 12, 1980)
}

\begin{abstract}
Nerve excitation is the time-dependent opening and closure of the sodium and the potassium channels, with the time course determined by the membrane potential and temperature. ${ }^{1)}$ Changing sodium and potassium concentrations inside and outside the axon, the shapes of action potential and membrane current changed. The magnitude of membrane current flowing through each channel was related to the concentration of each ion, with the time course unchanged.1) Besides ions, non-electrolytes added into solutions affected nerve excitation, ${ }^{2)}$ probably because they acted as obstruction in the passage of ions. Some kind of non-electrolytes penetrate through the ionic channel pores, ${ }^{3), 4)}$ so they might interact with ions. One of the marked effects of adding non-electrolytes was slowing of the time course of nerve excitation and decreasing sodium and potassium currents evenly, when the same non-electrolytes were added on both sides. $^{2)}$

We report here that the different size of non-electrolyte molecules, that is, permeable molecules and impermeable molecules added on each side of the membrane caused the uneven change in the membrane currents, depending on the direction of currents. In this condition, one kind of channel acted more effectively than the other one.

The intracellular perfusion of squid giant axon (Doryteuthis bleekeri) was performed according to the method of Tasaki and his collaborators. ${ }^{5)}$ Two types of non-electrolytes, that is, glycerol as permeable molecules and glucose and sucrose as impermeable molecules were used. Sometimes, ethylene glycol was used as permeable molecules. Concentrations of glucose inside and outside were (in M) 1.56 and 2.30, and those of glycerol were 2.43 and 3.58, respectively. The viscosities of glycerol solutions were smaller than those of corresponding glucose solutions. Although the osmolalities of glucose and glycerol solutions were about three times larger than that of the isotonic artificial sea water, they were matched to each other, considering the
\end{abstract}


permeability of these molecules. The molar concentrations of ions were the same in glucose and glycerol solutions and activities of cations were approximately equal, because water content and the activity coefficients of ions in these solutions were almost the same. ${ }^{6), 7)}$

Typical results of action potentials, their derivatives and membrane currents are represented in Fig. 1. When the external glucose solution was replaced with the glycerol solution, the rising phase of action potential was hastened with a small increase in the maximum

$\begin{array}{rllll}\text { Out: } & \text { gle } & \text { glyc } & \text { glyc } & \text { glc } \\ \text { In: } & \text { gle } & \text { glc } & \text { glyc } & \text { glyc }\end{array}$
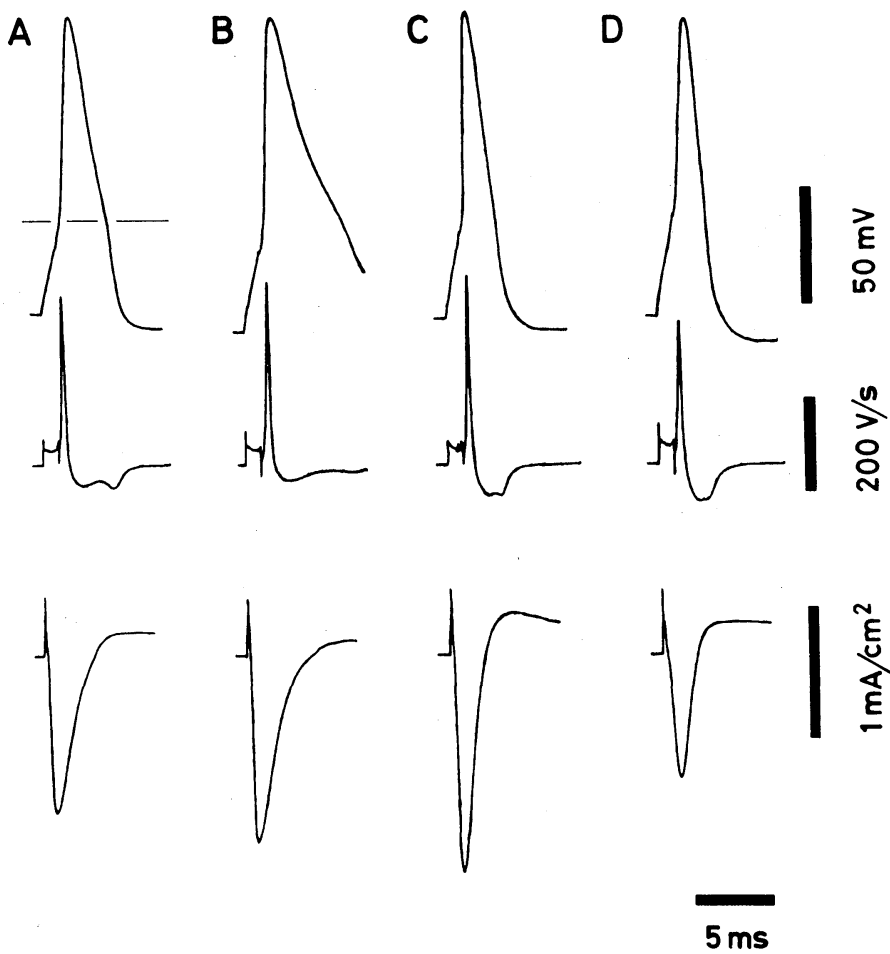

Fig. 1. Action potentials, their derivatives and the membrane currents at the clamping voltage of $70 \mathrm{mV}$. The holding potential was $-60 \mathrm{mV}$. Four pairs of the internal and external solutions were used. External solutions were glucose (glc) solutions (A and D) and glycerol (glyc) solutions (B and $\mathrm{C}$ ). Internal solutions were glucose solutions (A and B) and glycerol solutions (C and D). Concentrations of glycerol outside and inside (in M) were 2.43 and 3.58, and those of glucose were 1.56 and 2.30, respectively. External solutions contained (in $\mathrm{mM}$ ) $440 \mathrm{NaCl}$, $100 \mathrm{CaCl}_{2}$ and $10 \mathrm{mM}$ Na-HEPES ( $\mathrm{pH} \mathrm{8.0).} \mathrm{Internal} \mathrm{solution} \mathrm{contained}$ (in $\mathrm{mM}$ ) $80 \mathrm{KF}$ and $20 \mathrm{~K}^{+}$as phosphate buffer ( $\left.\mathrm{pH} 7.4\right)$. The solution temperature was $14^{\circ} \mathrm{C}$. 
rate of rise, while the falling phase of action potential was slowed. The duration of action potential increased compared with record A, in spite of the decrease in solution viscosity (record B). Frequently the action potential with a long plateau was observed in this condition. A resting potential somewhat hyperpolarized with a small decrease in the threshold potential (Fig. 2). The inward current increased by $20 \%$ (mean $22 \%$ ) and the time to peak inward current did not change. The outward current was slowed, with the amplitude decreased to $33 \%$ (mean $37 \%$ ) (record B). When the internal solu-

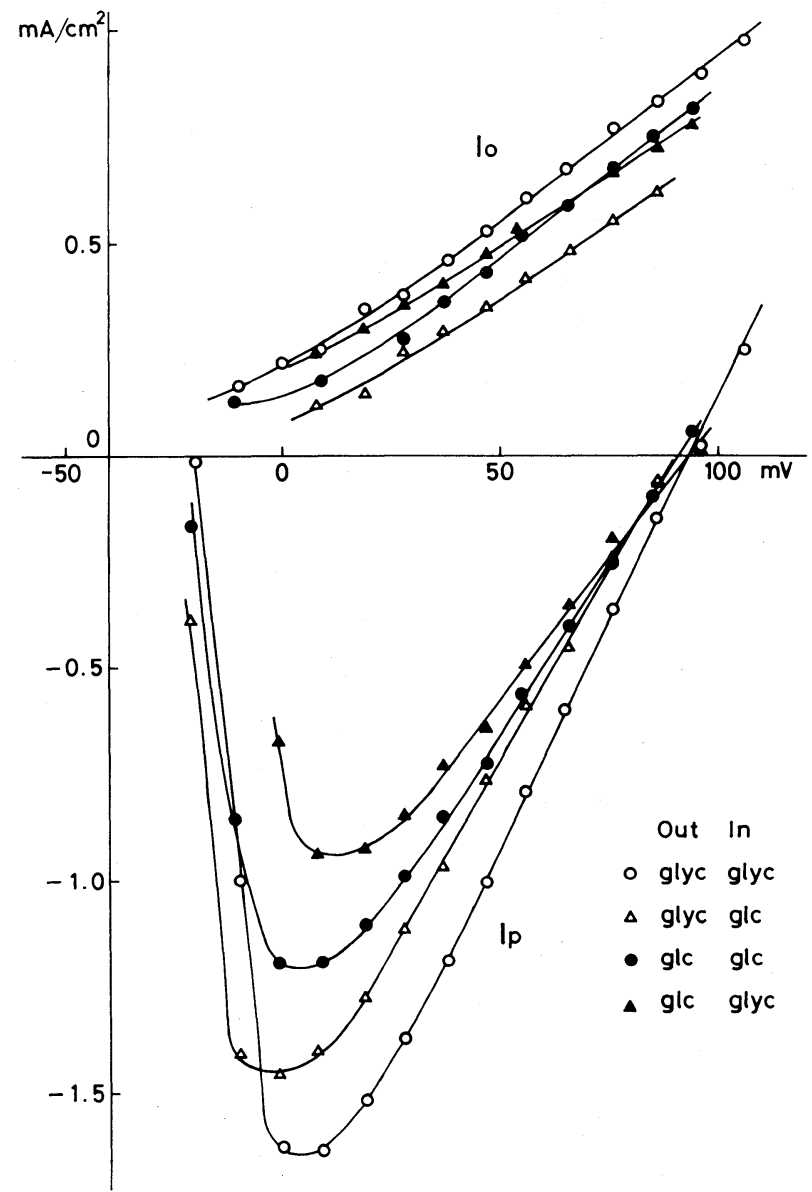

Fig. 2. The current-voltage relationship under the voltage clamp of the experiment shown in Fig. 1. The peak inward current (Ip) and the outward current $7 \mathrm{msec}$ after the stepwise change of membrane potential (Io) are plotted. External solutions were glucose solutions $(\bullet \Delta)$ and glycerol solutions $(O \triangle)$. Internal solutions were glucose solutions $(\triangle \bullet)$ and glycerol solutions $(\bigcirc \Delta)$. The holding potential was $-60 \mathrm{mV}$. 
tion was replaced with the glycerol solution also, the falling phase of action potential was hastened. The outward current was also hastened with the magnitude increased to twofold (mean 1.7-fold) of that in record $\mathrm{A}$ (record $\mathrm{C}$ ). The inward current further increased to 1.4fold. The shapes of the action potential and the membrane current resembled those in record $\mathrm{A}$, although the time course was hastened and the magnitude of membrane current increased, since solutions inside and outside were less viscous glycerol solutions. ${ }^{2)}$ With glucose outside and glycerol inside, the maximum rate of rise was smaller than that in record $A$, and the duration was smaller than that in record C (record D). The undershoot of falling phase became large. The resting potential somewhat depolarized with a small increase in the threshold potential (Fig. 2). The inward current was smaller than that in record A, while the steady outward current was almost the same as that in record C. All these effects appeared immediately after the solution change and were reversible.

The current-voltage relations in various solutions are represented in Fig. 2. At all clamping voltages, the peak inward current was larger with glycerol outside, while the outward current was larger with glycerol inside. The slope conductance of peak inward current decreased with glucose outside, while those of outward current changed little with the current-voltage relation curves shifted along the voltage axis.

The asymmetrical effects occurred when sucrose was used in place of glucose with glycerol on one side. But this effect did not occur when the impermeable molecules were used on both sides, for example, glucose on one side and sucrose on the other side. Ethylene glycol added into solutions showed the similar asymmetrical effect. Therefore, the permeability of non-electrolytes was important in these phenomena.

The outward potassium current was mostly inhibited by intracellular perfusion with the glucose solution containing $10 \mathrm{mM}$ TEA. With this preparation, the glucose solution outside being replaced with the glycerol solution, the prolongation of the action potential became more marked with a little increase in the maximum rate of rise. Glycerol outside increased the inward current carried by sodium ions, without any change in reversal potentials.

Decreasing or increasing glycerol outside, the asymmetrical effect on the action potential remained with the change in the time course. This shows that the small difference in physicochemical natures was not the cause of this asymmetrical effect.

When glycerol was added on one side and glucose on the other 
side, the ionic selectivity of the membrane changed, probably because of the difference in the non-electrolyte permeability. The diameter of the hydrated ions ${ }^{8,9)}$ which is the measure of the channel pore size, is larger than that of glycerol and smaller than that of glucose. ${ }^{3)}$ Probably, glycerol molecules penetrated into the pore from one side to cause the asymmetrical effects on the membrane currents, as if the ionic concentration on this side was raised. This was cancelled out by glycerol penetrated from the other side. Therefore, the dimension of the pore must be larger than that estimated from results of the ionic selectivity.9)

We thank the members of Ine Fishery Cooperative at Kyoto, Japan and Dr. K. Furuya and Mr. T. Sakai for their kindful help to perform this work.

\section{References}

1) Hodgkin, A. L.: The Conduction of the Nerve Impulse. Charles C. Thomas, Springfield (Ill.) (1964).

2) Kukita, F., and Yamagishi, S.: J. Membrane Biol., 47, 303-325 (1979).

3) Villegas, R., Blei, M., and Villegas, G. M.: J. Gen. Physiol., 48, 35-40 (1965).

4) Huang, L. M., Catterall, W. A., and Ehrenstein, G.: J. Gen. Physiol., 73, 839-854 (1979).

5) Tasaki, I., Watanabe, A., and Takenaka, T.: Proc. Nat. Acad. Sci. USA, 48, 1177-1184 (1962).

6) Lanier, R. D.: J. Phys. Chem., 69, 2697-2706 (1965).

7) Kukita, F.: Ph. D. Thesis of Dept. Phys., Fac. Sci., Univ. of Tokyo (1979).

8) Mullins, L. J.: J. Gen. Physiol., 43, suppl., 105-117 (1960).

9) Hille, B.: J. Gen. Physiol., 59, 637-658 (1972). 